\title{
Semantic satiation, forewarning, and decision latency'
}

Philip B. Gough and Nicholas L. Kohrman

INDIANA UNIVERSITY

\begin{abstract}
Abstraet
Sixteen Ss were asked to decide if pairs of words had the same meaning. It was found that asking $S$ to repeat one of the words 1 or $15 \mathrm{sec}$. in advance equally facilitated his decision. The results indicate that forewarning and not semantic satiation reduces decision latency. Problem

Fillenbaum (1964) has found that if $\mathrm{S}$ is asked to decide if two words have the same meaning, his decision is faster after repeating one of the words for $1 \mathrm{~min}$. than after repeating an unrelated word. This would appear to be evidence against semantic satiation, for if repetition of a word results in loss of meaning, repetition of a word should make more difficult a decision involving its meaning. But Fillenbaum suggests that continuous elicitation of a word may both lead to changes in meaning and alert $\mathrm{S}$ to specific word features, and so either facilitate or impair a decision involving that word.

However, Fillenbaum's results do not show that continuous elicitation has these effects, for in his studies the effects of repetition were confounded with those of simple forewarning. When $S$ was asked to repeat one of the decision pair, he knew one of those words in advance; when he repeated an unrelated word, he did not. We do not know whether decision latency was reduced by asking $S$ to repeat one of the decision words or simply by giving him that word prior to the decision.

This experiment was conducted to separate the effects of repetition (and hence semantic satiation) and forewarning on decision latency.

\section{Method}

Each of 16 college students was asked to decide if each of 16 pairs of words had the same meaning, and the latencies of their decisions were recorded. To assess practice effects the pairs were presented in two series
\end{abstract}

of eight (A and B). Within each series, four pairs were synonyms (S), four were not(NS). Prior to the presentation of each pair, S was given a foreword, either one of the pair (F) or an unrelated word (NF), which he repeated 2-3 times a sec. until the decision pair appeared. On half of the trials, $S$ repeated the foreword for $15 \mathrm{sec}$ (R), but on the other half he repeated it for only 1 .sec. (NR). One sec. is time for little repetition, and if it is repetition that reduces decisision latency there should be little reduction on NR, compared to $\mathrm{R}$, trials, and an interaction between repetition and forewarning should result. In sum, the items given to each $\mathrm{S}$ constituted a $2^{4}$ factorial design, practice (A-B) $x$ synonymity (S-NS) $x$ forewarning $(\mathrm{F}-\mathrm{NF}) \times$ repetition $(\mathrm{R}-\mathrm{NR})$.

Sixteen pairs of synonyms were drawn from Roget's Thesaurus; an unrelated word was assigned to each pair to substitute for one member in the NS condition. All 48 words were common and no more than eight letters long. The 16 pairs were assigned to conditions using a latin square, so that each pair occurred once in each condition, and each $\mathrm{S}$ received a different assignment.

All pairs were presented in a tachistoscope. A .01-sec. timer began with presentation and stopped when $\mathrm{S}$ pressed a button appropriate to the correct decision.

\section{Results and Discussion}

Mean decision latency for each type of item is presented in Table 1 . An analysis of variance revealed that forewarning reduced decision latency $(F=61.36$; $\mathrm{df}=1 / 15 ; \mathrm{p}<.01)$ as did practice $(\mathrm{F}=15.45 ; \mathrm{df}=1 / 15$; $\mathrm{p}<.01)$. The other factors had no significant effects, and there were no significant interactions (all Fs $<3.50$ ). In particular, it should be noted that repetition did not interact with forewarning; giving $S$ one of the decision words only $1 \mathrm{sec}$. before the decision facilitated his

Table 1. Mean Decision Latency in Sec.

\begin{tabular}{|c|c|c|c|c|c|}
\hline & & \multicolumn{2}{|c|}{ Forewarning } & \multicolumn{2}{|c|}{ No Forewarning } \\
\hline & & Synonyms & Unrelated & Synonyms & Unrelated \\
\hline First Series (A) & Repetition & 1.37 & 1.26 & 1.66 & 1.50 \\
\hline & No Repetition & 1.28 & 1.29 & 1.58 & 1.51 \\
\hline Second Series (B) & Repetition & 1.20 & 1.36 & 1.64 & 1.45 \\
\hline & No Repetition & 1.18 & 1.27 & 1.29 & 1.43 \\
\hline
\end{tabular}


decision as much as giving him that word $15 \mathrm{sec}$. in advance. Evidently repetition is not important, and it is forewarning, rather than semantic satiation, which reduces decision latency. There is no evidence, then, that continuous elicitation of a word has any effect on the difficulty of making a decision involving that word's meaning. These results, like those of Yelen \& Schulz (1963), Reynierse \& Barch (1963), and Schulz, Weaver, \& Radtke (1965) indicate that semantic satiation is a circumscribed phenomenon.
Referenees

FILLENBAUM, S. Semantic satiation and decision latency. J. exp. Psychol., 1964, 68, 240-244。

REYNIERSE, J. H., \& BARCH, A. M. Semantic satiation and generalization. Psychol. Rep., 1963, 13, 790 .

SCHULZ, R. W., WEAVER, G. E。, \& RADTKE, R. C.Verbal satiation?? Psychon. Sci., 1965, 2, 43-44.

YELEN, D. R., \& SCHULZ, R. W. Verbal satiation? J. verbal Learn. verbal Behav., 1963, 1, 372-377.

\section{Note}

1. These results were presented at the meetings of the Midwestern Psychological Association, Chicago, May 1, 1965. The study was supported by USPHS Grant MH 10568-01 to the senior author. 